\title{
LA FRAGMENTACIÓN DEL CUERPO FEMENINO Y LA DEGRADACIÓN DEL YO LÍRICO A PARTIR DE LA ESCRITURA FEMENINA EN LA MANO SUICIDA
}

\author{
Xinia Araya Jiménez
}

\begin{abstract}
RESUMEN
En el presente artículo, se analiza la obra de María Montero titulada La mano suicida, en la cual se presenta la conformación de la escritura lírica femenina a partir de la fragmentación del cuerpo femenino, así como su degradación como sujeto escritor. Se toma en consideración la clasificación atribuida por Francisco Rodríguez Cascante (2006) sobre la poesía costarricense contemporánea, en donde argumenta que la obra de Montero responde a la poesía individualista. De igual forma, se considerará la creación literaria como un medio de comunicación utilizado por el yo lírico para poner en evidencia su malestar social.

Palabras clave: La mano suicida, fragmentación, poesía femenina, degradación, Montero-María.
\end{abstract}

\begin{abstract}
This article analyzes the work of Maria Montero entitled La mano suicida, which shows the formation of the female lyric writing from the fragmentation of the female body and its degradation as a subject writer. It takes into consideration the classification attributed by Francisco Rodriguez Cascante (2006) on Costa Rican contemporary poetry, in which she argues that the work of Montero responds to individualistic poetry. Similarly, literary creation will be considered as the means of communication used by the lyrical first to bring out it's social unrest.
\end{abstract}

Key words: La mano suicida, fragmentation, feminine poetry, degradation, Montero-María.

\section{Introducción}

La poesía costarricense contemporánea ha incursionado en muchas vertientes como la poesía de análisis social, poesía cultural, amatoria, entre otras; pero todos estos tipos de poesía conversacional, como la denomina Rodríguez Cascante (2006), se han visto ampliamente influenciadas por las corrientes posmodernistas donde el sujeto enunciador (yo lírico) deja de considerarse trascendental y único, para ubicarse dentro del mundo lírico y constituirse como participante del mundo lírico. La obra de María Montero (2000), La mano suicida, presenta

\footnotetext{
Bach. Xinia Araya Jiménez. Bachiller en la Enseñanza del Castellano y la Literatura, actualmente cursa el grado de Maestría en la Enseñanza del Castellano y la Literatura de la Sede de Occidente, Universidad de Costa Rica. Correo electrónico: xiniaaj04@gmail.com
} 
una serie de poemas que están enfocados en la escritura femenina y su diferenciación con respecto al resto de la literatura. Por ello, el yo lírico reclama su lugar dentro de la sociedad y busca reivindicarse como individuo.

En su trabajo "La poesía costarricense contemporánea y el campo discursivo conversacional", Francisco Rodríguez propone que la poesía de María Montero se ubica dentro de lo que llama poesía individualista, en donde menciona que

\footnotetext{
(La poesía individulista) asume la construcción poética desde un distanciamiento de los grandes metarrelatos que asignan los sentidos de la modernidad, hay un esfuerzo en los textos de estos autores por abocarse a construir lo que Walter Mignolo llama historias locales, es decir, un pensamiento crítico que abre espacios a lugares, sujetos e ideas que fueron excluidos de los binarismos teóricos y literarios de la modernidad. (2006: 151)
}

El enfoque femenino y el interés por demostrar su situación son las características que dan pie a su incorporación dentro de este grupo de poesía individualista. Rodríguez Cascante habla en su trabajo que la poesía individualista rechaza todo nivel de representación social. Pero, el poemario de María Montero presenta ciertos indicios de la existencia de una colectividad, en el sentido de que la mujer y su situación representan una colectividad. Si bien como señala Rodríguez (2006: 152), la dimensión distanciada de los relatos, la soledad como espacio del sujeto, el distanciamiento de la solidaridad y la búsqueda de la convivencia recíproca son evidentes en la poesía individualista, Montero además presenta una preocupación por el re-planteamiento del sujeto (en este caso femenino) y su reivindicación social.

La obra de María Montero consta de tres conjuntos de poemas titulados "La mano suicida", "Días contados" y "Defectos especiales". En total, el poemario cuenta con 43 poemas. A continuación, se hará un análisis de algunos de los poemas para dar explicación a la situación del sujeto de enunciación y cómo, por medio de su enunciado, se puede determinar esa historia local a la que Rodríguez (2006) hace referencia. Seguidamente, se indagará la forma en que el yo lírico hace referencia al acto de la escritura y cómo, de la articulación de estos elementos, resulta la aceptación de la escritura femenina como degradación del sujeto.

\section{La mano es un emblema real}

El título del poemario es el primer indicio que tiene el lector sobre la temática que se expondrá a los largo de los poemas. La mano suicida hace referencia a dos polos antagónicos: la mano y la muerte. Según Jean Chevalier, "la mano da la idea de actividad, al mismo tiempo que la de potencia y dominio [...] la mano, por último, es símbolo de actitud diferenciadora" (2003: 682-685). Por otra parte, se encuentra la idea del suicido como fin, muerte y destrucción del yo. En el título, se concentra el fin que se aproxima, la mano como creación literaria lleva al ser a su propia destrucción.

En su primer poema, Montero presenta la mano como un miembro independiente. Argumenta Lucía Guerra (2006) que el cuerpo es el punto de referencia con el cual nos aproximamos a nosotras mismas; es decir, la mano en la poesía de María Montero viene a ser aquel fragmento del cuerpo femenino que conoce y escarba al ser

La mano suicida escarba en la basura

y me invita a acompañarla.

Busca desesperadamente lo perdido:

un ojo inalterable para el mundo,

la intimidad de antes (Montero 2000: 11) 
Con el fragmento anterior, se puede apreciar la función que tiene la mano dentro de los poemas; la mano es capaz de conocer y autoconocerse, la única que puede encontrar aquello que nadie más puede. Añadido a esto y retomando a Chevalier, la mano es símbolo de una actitud diferenciadora. En los poemas de Montero, esta actitud diferenciadora se encuentra en la escritura. Desde esta perspectiva, el yo lírico deja entrever que, por medio de la escritura, se va a conocer como individuo, el cual conforme avanza el poemario se va a encontrar en constante cuestionamiento y, por último, resignación.

La relación mujer/mano/escritura/poesía, Montero la deja clara en su segundo poema "Como si fuera poesía", en donde se presenta una mujer segura de sí misma que sale a la calle, contrario a lo que creen las personas, ella se considera bella. Así, la escritura femenina es considerada por muchos como muda o fea, pero la escritura femenina es transparente, deja ver otros escenarios y no le importa lo que piensen lo demás. Ella, en sí misma, se considera hermosa. Señala Guerra (2006: 178) que escribir (en el sentido de la mujer escritora), entonces, ha sido la manera de prolongar una libertad ilusoria y posponer una condena; la condena a la que está destinada la mujer es la incomprensión por parte del otro, como se evidenciará más adelante.

A partir del poema titulado "La única luz en el mundo", se inicia el proceso de degradación del sujeto. El yo lírico muestra en este poema su incapacidad de escribir, de darse a escuchar y de poder ver. Pasa de ser un sujeto que anteriormente se decía, para convertirse en uno que guarda silencio, soledad y tristeza; además, reclama por la incomprensión por parte del otro, por ejemplo, en el poema "Informa policial":

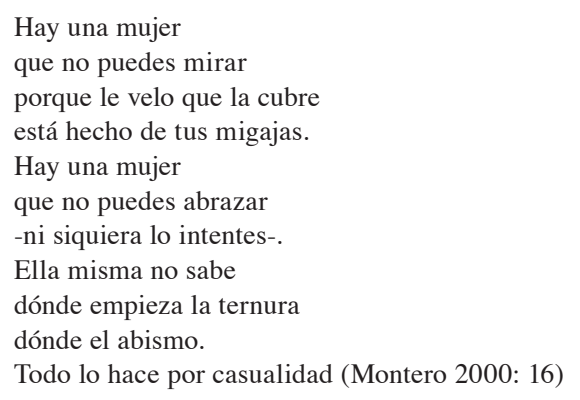

Este poema da un giro al texto completo, ya que marca una división entre la poesía con corte optimista, para dar paso a lo oscuro, a la incomprensión. La aparición de un tú lírico al que se apela en el poema anterior da muestras de ese reclamo que hace el yo lírico. Alguien es culpable de su situación, pero ese alguien al que yo lírico reclama es la sociedad y su estructura representada en la figura masculina. Por eso, los versos finales "Hay una mujer/que no puedes tener./ Es tan hombre como tú".

\section{Lo que significa ser mujer}

Tradicionalmente, se ha construido un perfil de mujer. Esta construcción responde a una serie de procesos sociales y culturales que se han desarrollado durante la historia. De acuerdo con Lucía Etxebarria (2000: 17), una tendencia natural del ser humano son las construcciones sociales destinadas a reforzar la separación artificial entre hombres y mujeres, apuntar a una distancia creada entre géneros para mantener una estructura de poder desequilibrada e injusta. Esta distancia que apunta Etxebarria queda demostrada en varios de los poemas de Montero, 
en donde se deja claro la diferencia de la escritura femenina, por ejemplo, en el poema "Vieja fotografía" cuando señala que

La que escribe su vida en las paredes

con lápiz de cejas

pintura de labios

o cualquier despojo que aparezca en el bolso (Montero 2000: 19)

Esa vieja fotografía muestra a la mujer, aquella que esconde y que vive en soledad. Añade Montero, a este poema, una descripción de lo que es ser mujer actualmente (y tradicionalmente), describe todos aquellos detalles que solo las mujeres pueden comprender, por ejemplo al decir "La que duerme sin tener sueño/ o se hace la dormida para estar más sola".

Una serie de poemas exponen esta temática de lo que es ser mujer y cómo esta situación influye en su creación, en su decirse. Por ejemplo, el tema de la maternidad que ha sido sumamente analizado por el supuesto de que la mujer debe ser madre ab natura, sin importar sus deseos. Montero expone esta problemática presentando un yo lírico que deseaba mucha más que solo ser madre. Según Guerra, la imposición de la maternidad como único rol social es para las escritoras actuales, uno de los eslabones que han dejado de existir (2006: 190). No obstante, para la sociedad y la mujer actual, la maternidad sigue siendo un rol social que tiene gran influencia en la vida de las mujeres, al grado de ser imposición. Dice Montero "Iba hacia las letras/ y llegué al embarazo, estos versos muestran la fuerte contradicción entre las letras y la maternidad, siendo de igual forma, las dos, creación y vida". Para el mundo social, la mujer no puede cumplir los dos roles, sino que debe elegir uno, primando siempre la maternidad.

Una vez presenta la construcción de mujer actual, que no es diferente a la mujer de épocas pasadas, la autora desea hacer un llamado a la colectividad, a la identificación con el otro y lo hace por medio de su poema "Soy", en el cual expone una serie de estereotipos de mujer, que simultáneamente, son el yo lírico: "Soy la gran Virginia Wolf [...] Soy Margarte Durás [...] Soy Simone de Beavoir [...] Soy la imbécil femme [...] Soy la puta más puta [...] Soy la pobre infeliz [...] Soy yo" (Montero 2000: 25-26). A través del poema, el yo lírico va mutando y así pasa de la clase aristocrática (representada por ejemplo en Virginia Wolf y Simone de Beavoir) hasta ser una puta en una calle o una madre soltera que es agredida, al final son todas, las mujeres son una serie de posibilidades y el llamado que hace el yo lírico es a construir un sujeto colectivo, una colectividad que represente a todas las mujeres que por siglos han sido calladas y dichas por los hombres.

Una vez situado en la colectividad, el poemario muestra su segundo apartado "Días contados", en donde, como señala Cecilia Secreto (1997), el cuerpo femenino se hace letra en la escritura. En esta sección, los poemas están enfocados en la corporalidad femenina y cómo las relaciones sociales están basadas en la unión o desunión de los cuerpos, degradando así la imagen de la mujer, como sujeto complejo y social, al minimizarla a su anatomía. Por ejemplo, el poema "El Gran Hotel de Medellín y otra leyes físicas", en donde "los vi/ se refugian en otros vivos y se aman de pie/ sobre las puertas y frente a las ventanas [...] Después de las bombas solo quedan fragmentos/ intacta la mano, un beso, las piernas, el abra/zo, el trance indestructible que va del placer ha/cia el horror" (Montero 2000: 32).

Es interesante observar la asociación que existe en la segunda parte del poemario basada en el cuerpo/placer/soledad; la mujer aunque siente placer físico, siempre se siente sola, porque ese placer no llena el vacío que le deja el no poder escribir, ni el no ser comprendida 
por medio de la escritura, lo cual se demuestra al decir el yo lírico "el trance indestructible del placer hacia el horror" o en su poema "Espejismo de la dicha" en donde

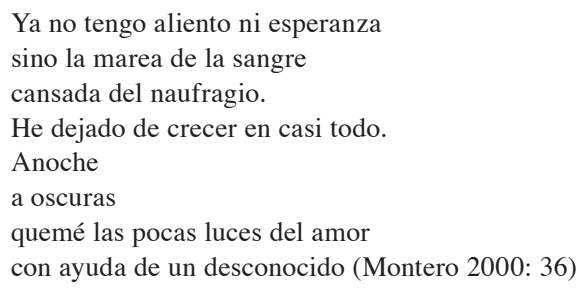

El sujeto de enunciación ha perdido toda la esperanza de ser entendido, ha dejado de crecer porque su escritura ya no es suficiente y el amor no existe. El yo lírico construido en los primeros poemas parece haber llegado a un nivel de conformación de su personalidad: ya no es un sujeto completo que se decía en la escritura; sino, más bien, es un sujeto que se siente insatisfecho porque la escritura, lo que pensó que lo iba a sacar del abismo, se ha convertido en un peso, ya que el acto femenino de escribir es señalado socialmente.

El desencanto producto de la escritura incomprendida queda evidenciado en el poema "Pos parto", un poema que hace referencia a un nuevo renacer cuando dice "Ya no te mantiene el asombro/ ni el deseo que alucinó/ en tus viejos libros. / Tu boca es una herida apresurada [...] Nunca más lo que fuimos" (Montero 2000: 43). Con este poema, se inicia una seguidilla entendidos como autorreclamos, el yo lírico se reclama a sí mismo, se llama la atención por esa actitud indiferente a su situación y por dejar que el cumplimiento de su rol social asignado la haya separado de la escritura completamente y la haya llevado a ese caos de desamor, desilusión y de soledad. El poema "Monólogo en tercera persona" es muestra de ese reclamo que se hace el yo lírico

Pídele al otro que vuelva

al desconocido

que arde para siempre bajo el sol de la

Habana.

Pídele que baile desnudo como un tonto

que persiga rabioso tu alegría

que tome un autobús

$\mathrm{y}$ en medio de la gente

te diga que está a punto de bajarse

porque eres una puta inaguantable.

Pídele a esa isla

a la que nadie te invitó:

la cerradura inmóvil

donde sólo pueden verse los amantes.

Pídele una croqueta

unos zapatos viejos

el largo camino de la entrega

y la canción que persigue incansable

la distancia entre el Malecón y el mundo.

Pídele lo que ya has perdido.

Pídele un padre para tus hijas

el gesto único que se anticipa al deseo

y los años que se esfuman

con el cuerpo mutilado del olvido (Montero 2000: 44-45) 
El poema anterior propone una reflexión, el yo lírico se da cuenta de que no está bien y de que tiene que propiciar un cambio, hay un enfrentamiento interior en donde se encara y se cuestiona a sí mismo, dando pie a un cambio que se reflejará en los poemas del tercer y último apartado del poemario. El epígrafe que presenta el texto anterior es significativo, ya que hace alusión a que no cambia su actual situación por su pasada, las ganas de un cambio se alimenta en el recuerdo de lo que fue antes y que ya no es.

\section{Una nueva actitud: la mujer y la escritora}

El poema anterior es el cierre de la parte titulada "Días contados" que, como puede entender el lector, hace referencia a los días últimos de un ser que se encuentra en degradación, en cuestionamiento constante de lo que hace y lo que piensa. El apartado finaliza con un llamado de atención sobre su condición y la conclusión a la que se llega está en la sección siguiente titulada "Defectos especiales". El título de la tercera sección es sintomático a la actitud final que asume la escritora; "Defectos especiales" hace referencia a la condición de la mujer y la mujer escritora que se asume y se acepta tal y como es, sin importar las condiciones sociales que la persiguen (y perseguirán); la escritura la llena y la complace y es en la escritura que logra conocerse, valorarse, aceptarse y darse a conocer al otro.

El poema que abre esta sección se titula "Sigo pensando en cómo educar a los lectores". Como se puede apreciar, el título es muy representativo de esta nueva actitud que asume el yo lírico. Desea que los lectores tengan la capacidad de comprender, conforme avanza el poema, se llega a la conclusión de que no es posible sensibilizar a los lectores y por ello "lo mejor para leer estas palabras/ es no pronunciarlas nunca. / Sacarlas de su silencia es su ruina" (Montero 2000: 57). El yo lírico llega a la conclusión de que la escritura femenina es incomprendida por el otro y de nada sirve hacerla leer, si no va a ser entendida ni valorada. La resignación al silencio que denota el poema es una derrota ante el posicionamiento social, pero, individualmente, es una nueva actitud que ha asumido el yo lírico frente a la impotencia que experimenta socialmente.

Dentro de esta selección de textos de la tercera parte, se encuentra "Horrotodoncia", poema que hace referencia al arte de escribir como horror

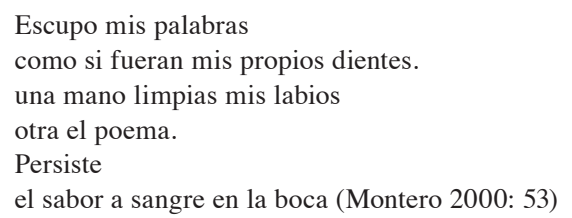

Para la mujer, escribir conlleva dolor, sufrimiento, despojarse de alto tan propio como los dientes. La imagen que ofrece el poema es desoladora; una mujer que pierde hasta algo vital por escribir y las palabras salen de su boca escupidas, no dichas sino que van con fuerza; salen con efusión y sin control. El sabor a sangre que sigue en la boca, es el sabor de la derrota, del sufrimiento, de la indiferencia, de la resignación; la mujer que está destinada a escribir tendrá que sufrir y ese sufrimiento será persistente en su vida.

La nueva actitud de asumirse como escritora a pesar de no saber a dónde llevará eso, crea incertidumbre. Esto queda expresado claramente en el poema "Adivinanza", donde el único verso que compone el poema dice más de lo que aparenta "Si sobrevivo, ¿qué haré?" (Montero 2000: 63); la agonía e incertidumbre se manifiestan en la impotencia de no conocer 
su destino, de no tener claro todavía qué va a pasar. Para este punto, el yo lírico se ha quedado sin mano (creación), sin palabras (porque han muerto), sin poesía (porque su cuerpo ya no funciona como poesía), al verse totalmente degradada solo queda cuestionarse el ¿y ahora qué? La cuestión posmoderna e individualista se fisionan en una línea, para dar a entender el sentido del poemario: si la mujer no es mano, no es cuerpo, no es palabra ¿qué es? La mano suicida es la única capaz de dar la respuesta.

El poema que cierra esta tercera sección (y por ende el poemario) tiene por título "Referencias literarias" y cuenta cómo el yo lírico se ha asumido completamente como escritora y como persona

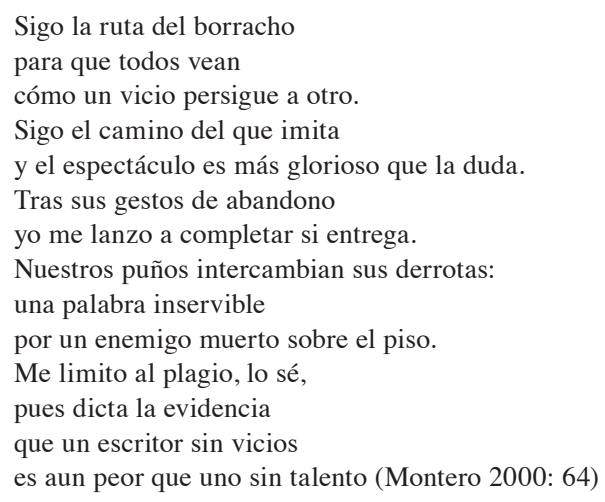

La escritura es un vicio del que no se puede escapar, si la mujer la practica, será señalada por ello; pero, al dejarla, ella se sentirá incompleta, vacía y caerá -como en la segunda sección- convirtiéndose en un sujeto vacío y en crisis. Al final del texto, se presenta un yo lírico dispuesto a asumir las críticas por su escritura, un sujeto que no es feliz, pero que por lo menos se dedica a la escritura, aunque ni siquiera puede ser considerada como suya, porque socialmente la mujer solo puede copiar las creaciones ya instauradas. La mano, como símbolo de la escritura, se ha convertido en su propia perdición, de ahí su adjetivo de suicida; es la misma mano, miembro propio de su cuerpo la encargada de conocer, pero también de matar. De nuevo, se vuelve al binomio inicial: la mano que es creación y autoconocimiento, a su vez, es destrucción y perdición.

\section{Conclusión}

La literatura costarricense contemporánea ha experimentado una serie de cambios que son respuesta a la época donde se está desarrollando. La poesía no es la excepción. La obra de María Montero, publicada en el año 2000, hace alusión a un número de tópicos presentes en nuestra sociedad actual, como lo son la soledad, la desolación, la incertidumbre, el desencanto. Todos estos tópicos están relacionados con la posmodernidad. Pero, más allá de eso, la poesía de Montero hace un llamado a un sector social que, a través de los años, ha sido dejado de lado por la misma dinámica social: las mujeres.

En sus poemas se presenta la mujer, pero no como un todo, sino que su mano viene a fungir como sinécdoque de su cuerpo y, al mismo tiempo, metonimia del acto de escritura. El sujeto enunciador o yo lírico es una sujeto que está en cuestionamiento, presenta una crisis de identidad al no encontrarse feliz en el rol social que le ha sido asignado; añadido a esto, 
socialmente, el acto de escribir (una mujer escritora) ha sido considerado un defecto. Para el yo lírico de los poemas, la escritura era su medio de escape, de conocerse y darse a conocer, de decirse. Pero, esta escritura solo amplía la brecha existente entre hombres y mujeres al considerar la escritura femenina como algo inservible y poco productivo (valores de uso, valores de cambio).

La condición degradada del sujeto no es individual, como propone Rodríguez (2006), sino que existe una complicidad entre las mujeres como género, como colectividad. Todas se sienten identificadas con la poesía, porque les ha tocado vivir, en mayor o menos medida, la institución social y sus reglas. Por ejemplo, no importa qué puesto o cargo tenga la mujer, ella primero debe estar dedicada a la casa y luego sus otros deberes. La maternidad no es una elección, sino es un deber y el darse a los demás a cambio de nada es pan de cada día.

La poesía de Montero no puede ser llamada feminista, a pesar de su tomo social. Esto porque no busca la lucha o la oposición con el hombre, sino que su interés es generar en la conciencia social un respeto hacia lo que es propio de la mujer y su escritura. Busca que el otro (hombre) comprenda a la mujer (que siempre ha sido asignada bajo el título de "el otro"). Para lograr este acercamiento, utiliza la poesía como comunicación. Por medio de ella, intenta dar a entender cómo se siente, cuáles son sus preocupaciones.

Al final de la lectura, los poemas dejan un sin sabor en la boca sobre lo que está pasando con la figura de la mujer, ¿es solamente valorada por su cuerpo?, ¿acaso su escritura no ha sido nunca entendida? Las imágenes que presenta Montero en su poemario crean en el lector una preocupación. La mujer se presenta como un sujeto solitario, degradado, fragmentado que no tiene esperanzas de un cambio; bien lo dice la autora en su poema "Oraciones", al proponer la reivindicación, empezando por uno mismo

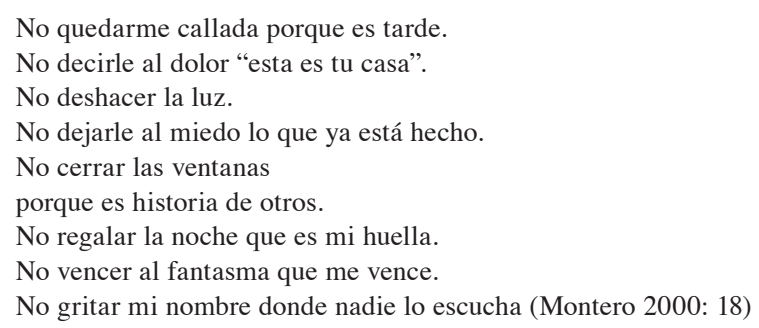

La propuesta que hace María Montero en su poemario es un llamado de atención a todas aquellas mujeres que han dejado lo que les apasiona por lo que les corresponde, la escritura viene a ser una forma de conocimiento, de autoreflexión. La mano que fue algún día creación, ahora es destrucción porque socavó tanto en la basura que encontró un ser totalmente incompleto y por ello se ha convertido en suicidio, porque dio a conocer todo aquello que faltaba y que ahora crea un vacío interior. Al final, la propuesta de Montero es una aceptación de la situación, esos defectos especiales que posee la mujer son los mismos que la llevan a salir adelante en una sociedad donde nunca ha tenido la oportunidad de decirse y de darse conocer, por el contrario, donde siempre ha sido dicha, encajonada y arrinconada en sus casas. El interés de Montero por presentar estos cuadros femeninos radica en lo que Cecilia Secreto (1997) señala al decir que la mujer que escribe, promueve, desde su palabra, una reivindicación, recupera la memoria del silencio; el objetivo de Montero no es crear controversia como se dijo anteriormente, por el contrario es mostrar una situación de la que las personas no tienen conciencia porque nunca ha sido dicha antes. 


\section{Bibliografía}

Chevalier, Jean y Alain Gheerbrant. 2003. Diccionario de símbolos. Barcelona: Herder Editorial.

Etxebarria, Lucia. 2000. La Eva futura. Barcelona: Destino.

Guerra, Lucia. 2006. La mujer fragmentada. Historias de un signo. Santiago: Cuarto Propio.

Montero, María. 2000. La mano suicida. San José: Perro Azul.

Rodríguez, Francisco. 2006. "La poesía costarricense contemporánea y el campo discursivo conversacional”. Káñina, Revista de Artes y Letras. 30 (2): 145-161.

Secreto, Cecilia. 1997. "Herencia femeninas: nominalización del malestar". En: Mujeres que escriben sobre mujeres (que escriben). Buenos Aires: Biblos. 
